\title{
Effect of Cathodic Charging on Al-32Si-2Cu Alloy in Acidic Solution
}

\author{
Antonyraj Arockiasamy, ${ }^{\mathrm{a},{ }^{, *}}$, Dan Eliezer ${ }^{\mathrm{a}}$, Paul Tzuupo Wang ${ }^{\mathrm{b}}$, Mark Fredrick Horstemeyer ${ }^{\mathrm{b}}$, Roger Lee King \\ ${ }^{a}$ Department of Materials Engineering, Ben-Gurion University of the Negev, \\ Beer-Sheva, Israel \\ ${ }^{\mathrm{b}}$ Center for Advanced Vehicular Systems, Mississippi State University, \\ 200 Research Boulevard, Starkville, MS 39759, USA
}

Received: March 3, 2010; Revised: July 15, 2010

\begin{abstract}
Samples of Al-32Si-2Cu intermetallic was subjected to electrochemical cathodic charging and corrosion test in hydrochloric acid $(\mathrm{HCl})$ solution of concentrations ranging from 0.1 to $3.0 \mathrm{M}$. The influence of cathodic charging current density and time on changing the surface morphology, phase transformation, compositions, and fracture mode has been investigated using X-ray diffraction (XRD) and scanning electron microscope (SEM) coupled with energy dispersive spectroscopy (EDS). A considerable drop in Vickers microhardness value with increasing cathodic charging time of the specimen was observed. Electrochemical polarization facilitates the formation of simple and mixed salt $\left(\mathrm{AlCl}_{3}, \mathrm{Al}_{5} \mathrm{Cl}_{3}(\mathrm{OH})_{12} \cdot 2 \mathrm{H}_{2} \mathrm{O}\right)$ over the alloy surface by chloride inclusion in the major corrosion product of hydroxides or oxides of Al.
\end{abstract}

Keywords: cathodic charging, potentiodynamic polarization, Al-32Si-4Cu alloy

\section{Introduction}

The demand for the consumption of light weight aluminum alloys with improved properties is continuously increasing in automobile industries. In recent years, one particular interest is being given to develop components that explore the properties of high strength to weight ratio, low thermal expansion coefficient, excellent mechanical properties, and ability to resist wear at high temperatures. In this aspect, Al-Si alloys containing copper, magnesium, manganese, zinc, and iron have been considered as a potential candidate to meet their requirements because of silicons ability to dissolve extensively at high temperatures and form homogeneous phase in the aluminum matrix. However, these alloys suffer catastrophic failure when exposed to an environment containing hydrogen and chloride due to hydrogen permeation and corrosive attack. A recent literature survey revealed that most of the research articles have been published from different alloy systems, very little research articles are available on the Al-silicon ( $\mathrm{Si}$ )-copper $(\mathrm{Cu})$-magnesium $(\mathrm{Mg})$-manganese $(\mathrm{Mn})$ alloys. For example, a 7020 aluminum alloy in $3.5 \% \mathrm{NaCl}$ solution showed that hydrogen embrittlement essentially operated where microcracks exist at the smooth surface of the specimens by mechanical failure or anodic dissolution ${ }^{1-4}$. Support for the formation of hydrides ${ }^{5-7}$ leading to hydrogen embrittlement ${ }^{8-12}$, and anodic dissolution of various $\mathrm{Al}$ alloys in different corrosive environments is extensive. Studies on improving the environmental cracking either by changing the morphology of grain precipitates during aging treatments ${ }^{13,14}$ or by the addition of different alloying elements are limited. T7 and T73 heat treatments greatly changed the microstructure and slip character on $\mathrm{Al}-\mathrm{Zn}-\mathrm{Mg}$ alloys ${ }^{7,15-19}$ and improved the resistive properties of stress corrosion cracking (SCC) ${ }^{20,21}$ and corrosion fatigue growth rates ${ }^{22}$ and decrease in fatigue resistance on $\mathrm{Al}-\mathrm{Mg}-\mathrm{Li}^{23}$ and $\mathrm{Al}-\mathrm{Cu}-\mathrm{Li}-2090$ alloy $^{24}$ in hydrogen environment was also reported. In addition, the susceptibility for pitting corrosion of various other $\mathrm{Al}$ alloys when it is used as an anode material has been reported ${ }^{25-38}$. The purpose of the present contribution is to investigate the influence of electrochemical cathodic charging and corrosion behavior of $\mathrm{Al}-\mathrm{Si}-\mathrm{Cu}$ alloy in hydrochloric acid solutions of concentration ranging from 0.1 to $3 \mathrm{M}$.

\section{Experimental Method}

\subsection{Cathodic charging}

An aluminum alloy containing a higher Si content than normal was used in this study. Casting procedure was employed to prepare the alloy, and its composition is given in Table1. Cathodic charging was carried out in $\mathrm{HCl}$ of 0.1-3.0 M concentration with two distinct current densities of 25 and $50 \mathrm{~mA} \mathrm{~cm}^{-2}$ in different durations of 24 , 48 , and 120 hours. The acid concentrations chosen in this study are useful for common industrial applications such as chemical cleaning and processing, acid treatment of oil wells, and other applications $^{39,40}$. The thickness of the specimen was $0.5 \mathrm{~mm}$. Prior to cathodic charging the electrodes were mechanically polished by using different grades of emery papers to remove the barrier oxide film. The mass changes before and after cathodic charging experiments were measured by a microbalance with an accuracy of $\pm 1 \mu \mathrm{g}$.

\subsection{Vickers microhardness}

Vickers hardness measurements under a load of 100 gf and a testing time of 10 seconds were also performed on each sample in at-least 6 different locations to evaluate the hardness of the specimen.

\subsection{X-ray diffraction studies}

$\mathrm{XRD}$ analyses was carried out on the bulk and of the hydrogenated specimen at a scanning rate of $1 \mathrm{deg} / \mathrm{min}$ in $2 \theta$ ranging from $20-100^{\circ}$ with a step size of $0.02^{\circ}$ using a Japanese Rigaku $D_{\max }$ $v_{\mathrm{A}}$-ray diffractometer with high intensity of $\mathrm{CuK} \alpha$ radiation $(\lambda=0.151478 \mathrm{~nm})$.

\subsection{Microstructural studies}

Scanning electron microscopy (JEOL 840 SEM) coupled with energy dispersive spectroscopy (EDS) was used to study the change in surface morphology and the nature of the film. 
Table 1. The chemical composition of the alloy wt. (\%).

\begin{tabular}{cccccc}
\hline $\mathrm{Cu}$ & $\mathrm{Si}$ & $\mathrm{Fe}$ & $\mathrm{Mg}$ & $\mathrm{Ti}$ & $\mathrm{Al}$ \\
\hline 2.6 & 3.5 & 0.01 & 0.01 & 0.01 & balance \\
\hline
\end{tabular}

\subsection{Potentiodynamic polarization}

Potentiodynamic polarization was performed in a conventional one compartment three-electrode Pyrex glass cell with a capacity of $400 \mathrm{~mL}$. Prior to polarization, the electrode was subjected to mechanical polishing by different grades of SiC emery paper followed by acetone cleaning to remove the contaminants/oxides on the surface before subsequently rinsing in ultrapure water. The area of the working electrode was $0.3 \mathrm{~cm}^{2}$. A platinum foil with a geometric area of $1 \mathrm{~cm}^{2}$ and a saturated calomel electrode (SCE) was used as a counter and reference electrode respectively. All experimental solutions were prepared by using ultrapure water and chemically pure $\mathrm{HCl}$ and all experiments were performed at ambient temperature of $24 \pm 1{ }^{\circ} \mathrm{C}$ and atmospheric pressure of $760 \mathrm{~mm} \mathrm{Hg}$ with a potentiostat and galvanostat (EG \& G, PARC 273A) controlled by M270 software using an IBM-type PC-486 microcomputer. Polarization was carried out $1.0 \mathrm{~V}$ from rest potential towards both anodic and cathodic directions in $0.1,1.0,2.0$, and $3.0 \mathrm{M} \mathrm{HCl}$ solutions and obtained the corresponding polarization curves. From the polarization curves the corrosion kinetic parameters such as Eop, Ec, Ic, ba, bc and corrosion rate were evaluated. The surface morphology was examined by SEM and the nature of the corrosion product was analyzed by XRD.

\section{Results and Discussion}

When $\mathrm{Al}$ is polarized in aqueous $\mathrm{HCl}$ solutions, the following cathodic and anodic reactions are feasible.

At the anode (Equations 1 and 2)

$$
\begin{aligned}
& \mathrm{Al} \rightarrow \mathrm{Al}^{3+}+3 \mathrm{e} \mathrm{Eo}=-1.662 \mathrm{~V} \\
& \mathrm{Cu} \rightarrow \mathrm{Cu}^{2+}+2 \mathrm{e} \mathrm{Eo}=+0.337 \mathrm{~V}
\end{aligned}
$$

At the cathode (Equations 3 and 4)

$$
\begin{aligned}
& 2 \mathrm{H}^{+}+2 \mathrm{e} \rightarrow \mathrm{H}_{2} \mathrm{Eo}=+0.000 \mathrm{~V} \\
& 2 \mathrm{Cl}^{-} \rightarrow \mathrm{Cl}_{2}+2 \mathrm{e} \mathrm{Eo}=+1.36
\end{aligned}
$$

According to e.m.f. series, reactions 1 and 3 are energetically favored more than the other two reactions. The anodic dissolution of $\mathrm{Al}$ present in the alloy is governed by three electron process primarily by the transfer of $\mathrm{Al}^{3+}$ ions at the metal-oxide interface ${ }^{41}$. This dissolution is proceeded with the formation of an intermediate species such as $\mathrm{Al}^{+}$or $\mathrm{Al}^{2+}{ }^{[42-44]}$. Even though pure $\mathrm{Al}$ is insensitive to hydrogen environments ${ }^{45,46}$ during cathodic charging, many articles reported the hydrogen embrittlement phenomena ${ }^{47-55}$, dislocation mobility ${ }^{56}$ and reduction of ductility ${ }^{57}$ when it is coupled with reactive metals or used as cathode in an electrochemical energy devices.

\subsection{Effect of hydrogen on vickers microhardness}

Figure 1 shows the variation of mass change during hydrogenation in different charging time and current density. The weight of the specimen was gradually decreased with charging time and the decrease was more influenced at high current density and charging time. The change in $\mathrm{pH}$ of the solution near the vicinity of the electrode due to preferential dissolution of $\mathrm{Al}$ and hydride formation is the main reasons for the decrease. The relationship between the hardness effects with charging time is presented in Figure 2.

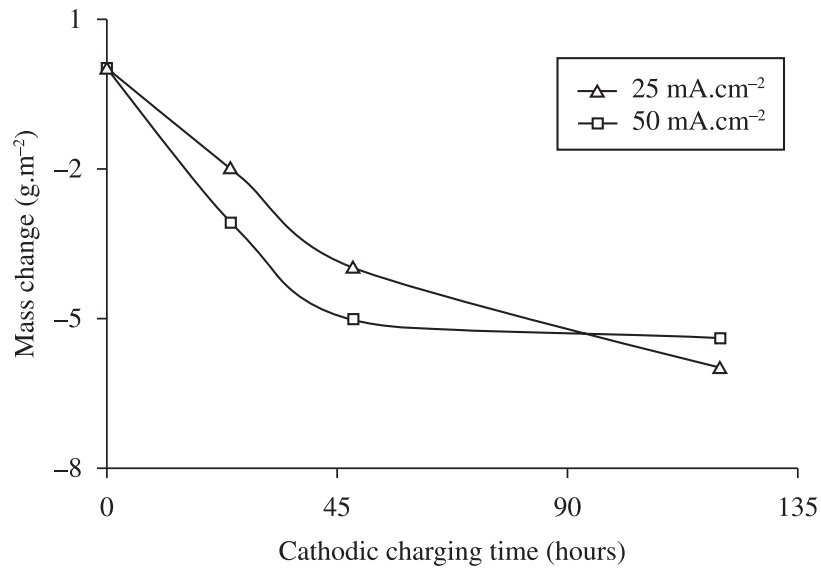

Figure 1. Weight change of Al-32Si-2Cu alloy after cathodic charging at 25 and $50 \mathrm{~mA} . \mathrm{cm}^{-2}$

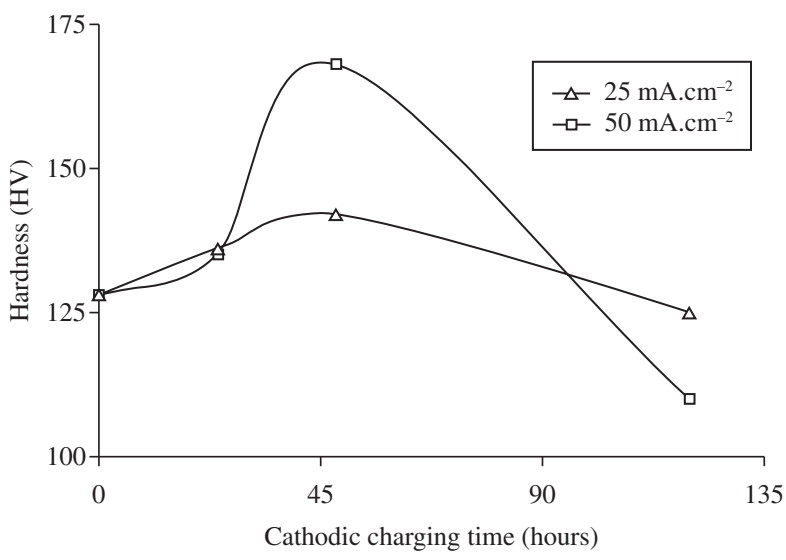

Figure 2. Effect of cathodic charging time on Vickers microhardness of Al-32Si-2Cu alloy hydrogenated at 25 and $50 \mathrm{~mA} . \mathrm{cm}^{-2}$

Increase in VHN values increase at initial stage of charging and start to decrease with further increase in charging time at both current densities revealed high dislocation mobility caused by high hydrogen dissolution, which in turn reduces the surface hardened layer by the formation of brittle compound such as $\mathrm{AlH}_{3}$. Moreover non-uniform distribution of dislocation bands and weakened grain boundaries formation due to over loaded hydrogen may also be a substantial reason for the decrease in VHN values.

\subsection{Effect of hydrogen on lattice parameters}

$\mathrm{X}$-ray diffraction patterns of the alloy in as-received and hydrogenated specimens at 25 and $50 \mathrm{~mA} . \mathrm{cm}^{-2}$ are presented in Figures 3 and 4. Sharp and well defined x-ray peaks, originated at an angle of 38.72 and 65.4 with hkl values of 14 and 10, were identified as $\delta$ - $\mathrm{Al}_{4} \mathrm{Cu}_{9}$ (JCPDS 24-3). The decrease in intensity of these peaks up to $48 \mathrm{hrs}$ showed the transformation of crystalline state or by the change in volume fraction of $-\mathrm{Al}_{4} \mathrm{Cu}_{9}$ phases. With a further increase in charging time, the intensity of the peaks obviously increased which indicates the partial reversibility of such transformation due to the establishment of atomic level strain and grain refinement of overloaded hydrogen. These studies also found the formation of $\mathrm{AlH}_{3}$ (JCPDS 14-1436) at an angle of $75.12^{\circ}$ particularly at high charging time and current density. Moreover the formation of readily soluble $\mathrm{AlCl}_{3}$ (JCPDS 77-0819) at 


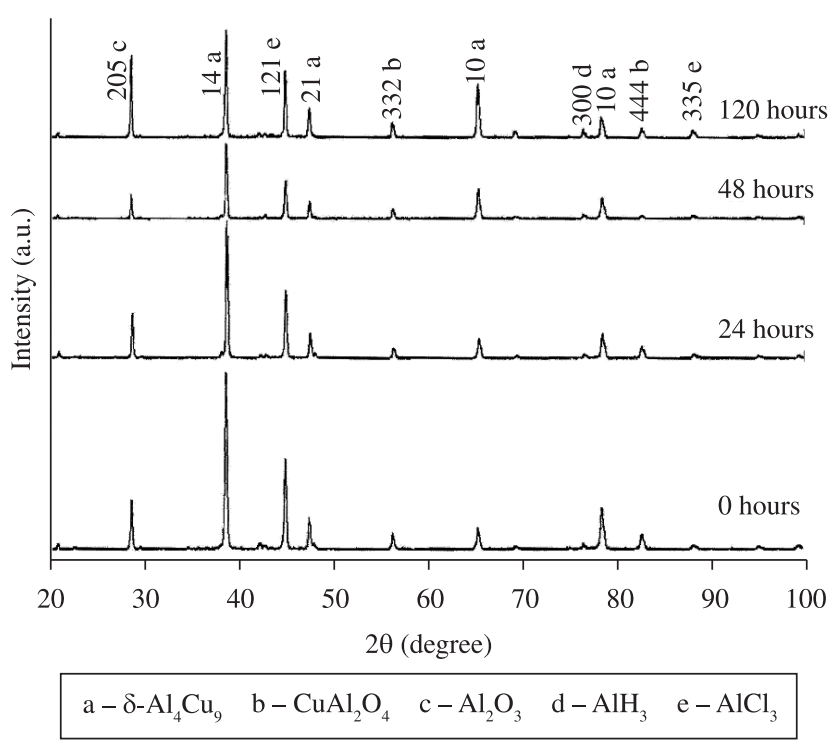

Figure 3. X-ray diffraction patterns of $\mathrm{Al}-32 \mathrm{Si}-2 \mathrm{Cu}$ alloy before and after cathodic charging in $0.1 \mathrm{M} \mathrm{HCl}$ at $25 \mathrm{~mA} \cdot \mathrm{cm}^{-2}$.

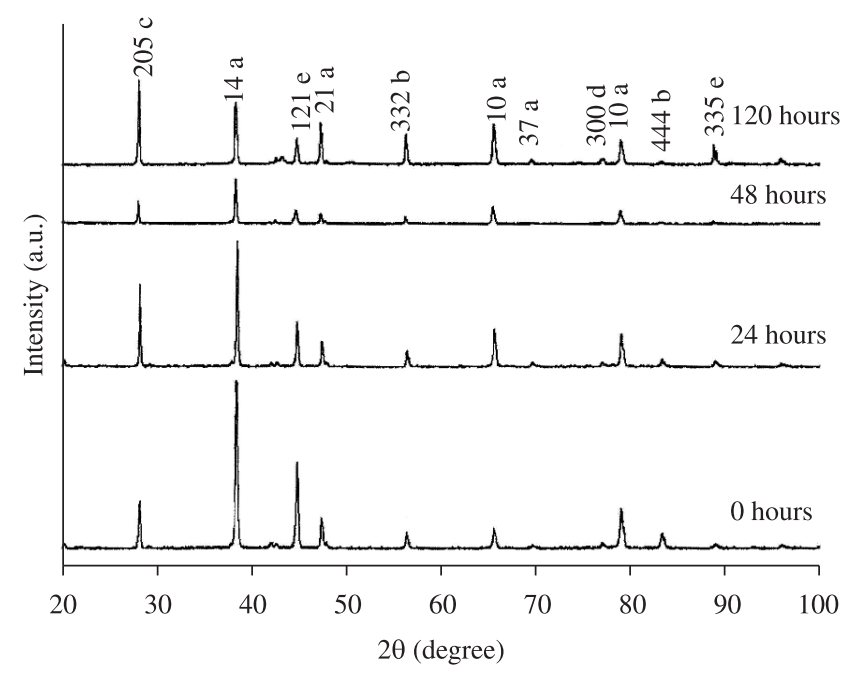

$\mathrm{a}-\delta-\mathrm{Al}_{4} \mathrm{Cu}_{9} \quad \mathrm{~b}-\mathrm{CuAl}_{2} \mathrm{O}_{4} \quad \mathrm{c}-\mathrm{Al}_{2} \mathrm{O}_{3} \quad \mathrm{~d}-\mathrm{AlH}_{3} \quad \mathrm{e}-\mathrm{AlCl}_{3}$

Figure 4. X-ray diffraction patterns of Al-32Si-2Cu alloy before and after cathodic charging in $0.1 \mathrm{M} \mathrm{HCl}$ at $50 \mathrm{~mA} . \mathrm{cm}^{-2}$

88.22 ${ }^{\circ}$ and insoluble $\mathrm{Al}_{2} \mathrm{O}_{3}$ (JCPDS 05-26471) and $\mathrm{CuAl}_{2} \mathrm{O}_{4}$ (JCPDS $01-1153)$ at $28.64^{\circ}$ and $75.12^{\circ}$ by chloride and oxygen incorporation have also been found in acidic medium.

\subsection{Effect of hydrogen on microstructure}

SEM images of hydrogenated alloy show different fractographic morphology which mainly depend upon both charging current density and time. Production of hydrogen and hydrous aluminum oxides at the gas-metal interface when aluminum is in contact with aqueous environment may cause two types of environmental effects namely hydrogen embrittlement and oxide barrier effects. Hydrogen absorption at the crack tip surface or by hydrogen - metal interface greatly reduces the fatigue resistance ${ }^{9}$. The latter may reduce the crack propagation rate due to oxide-induced crack closure by the formation of hydrous aluminum oxides on crack flanks ${ }^{58}$.

The SEM images of the alloy charged at $25 \mathrm{~mA} . \mathrm{cm}^{-2}$ for 24 hours in Figure 5a showed an elongated, shallow dimple with slip offsets which indicate cracking along slip planes and produce rugged fracture surfaces with primarily transgranular cracking combined with some intergranular delamination. The ductile type cracking commonly observed at low charging time on $\mathrm{Al}-\mathrm{Si}-\mathrm{Cu}$ alloy disappeared and was replaced with a relatively rough and irregular fracture appearance at high charging time. SEM images show the morphology of oxide layers (Figure 5b) and fracture characteristics (Figure 5c) on the alloy surface charged at $25 \mathrm{~mA} . \mathrm{cm}^{-2}$ for 48 and 120 hours respectively.

The SEM images of the alloy charged at $50 \mathrm{~mA} \cdot \mathrm{cm}^{-2}$ for 24 , 48, and 120 hours are shown in Figure 6. It should be noted that these fracture planes considerably deviate from the normal mode of fracture with increased current density and charging time. Even though hydrogen embrittlement phenomenon is associated with serious processes, the overall crack growth depends upon the rate at which it is absorbed into the materials. Very low diffusion of hydrogen and theories associated with dislocation transport of hydrogen for aluminum alloys have been proposed in order to account for the hydrogen embrittlement phenomenon ${ }^{59,60}$.

EDS analysis was performed to understand the compositional changes on the alloy surface. Table 2 shows the compositional changes around the surrounding matrix. More oxide formation and chloride inclusion in the crack tip and fracture surface was clearly evident from Figure. 7. The distribution of non-uniform clusters of oxides was seen on the surface (Figures 5 and 6) which reduces the initiation of cracks.

Also microstructural observation and compositional analysis proved the distribution of different sized intermetallic particles. The composition of the distributed intermetallic particles deviated slightly from the bulk specimen. These changes may be due to the effect of hydrogenation leading to the transformation of particles. SEM observations under high magnification showed no distinct sign of dendrite structure. The defects arising during hydrogenation are matrix void formation and disappearance of fine crystalline particles, and segregation of crack in the hydrogen concentrated region. The experimental results further indicated that the alloy structure was not only changing by charging time but also dependent on cathodic current density. If it is assumed that the low charging time has little effect on fracture of the alloy, the variation in crack propagation at a particular current density must be attributed to the microstructural changes of the material with charging time. Figures 5 and 6 show numerous microcracks on the surface of the sample indicated the brittle nature of the compound played a significant role in crack.

\subsection{Corrosion studies}

\subsubsection{Open circuit potential}

The variation of open circuit potential with immersion time in $0.1,1.0$ and $2.0 \mathrm{M} \mathrm{HCl}$ solutions is shown in Figure 8. Initially the anodic current of alloy is increased and then reaches a steady state value. These results reveal that the improvement of pitting corrosion resistance insignificantly reduced. An anodic current density value which surprisingly first increases and then decreases in $3.0 \mathrm{M} \mathrm{HCl}$ indicates that the initiation of pit growth rate is considerably lower. The increased pitting susceptibility in acidic chloride solution may be due to the decreased resistance of the surface film by incorporation of $\mathrm{H}^{+}$ion into the film ${ }^{61,62}$ which creates a way to incorporation of $\mathrm{Cl}^{-}$ions to initiate pit into the film. A number of fluctuations seen in OCP may be attributed to the pitting activity of chloride ions ${ }^{63-65}$. OCP attainment towards negative values may be ascribed to the growth of 


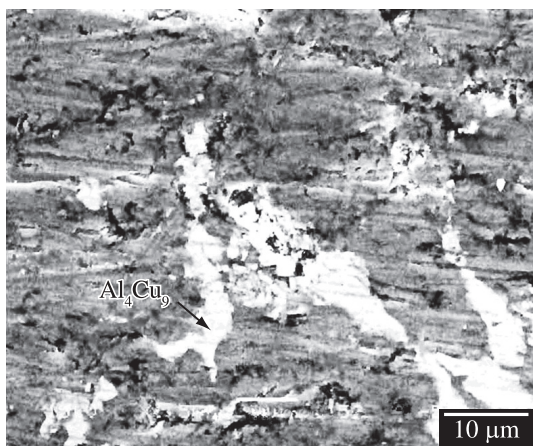

(a)

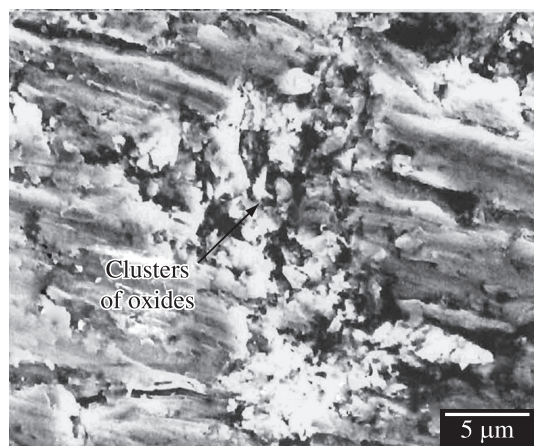

(b)

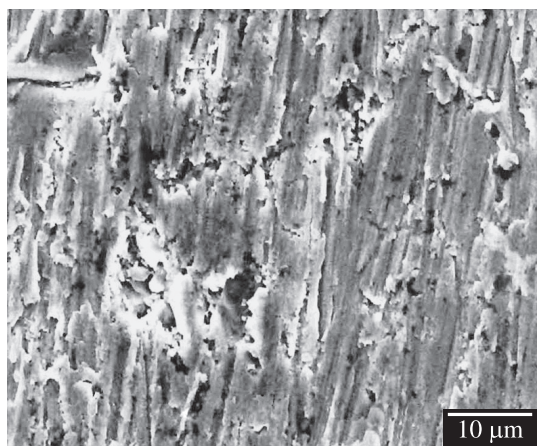

(c)

Figure 5. Scanning electron micrographs of the Al-32Si-2Cu alloy charged at $25 \mathrm{~mA} . \mathrm{cm}^{-2}$ for a) 24 hours; b) 48 hours; and c) 120 hours.

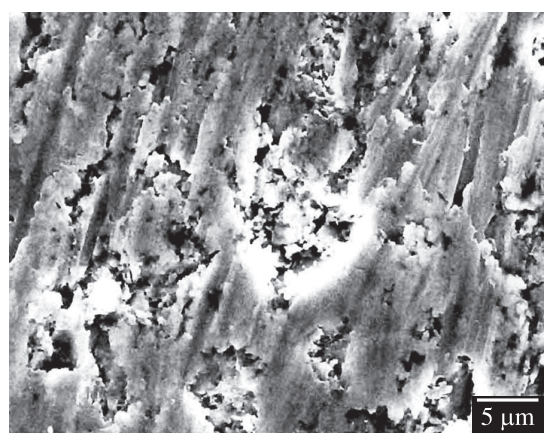

(a)

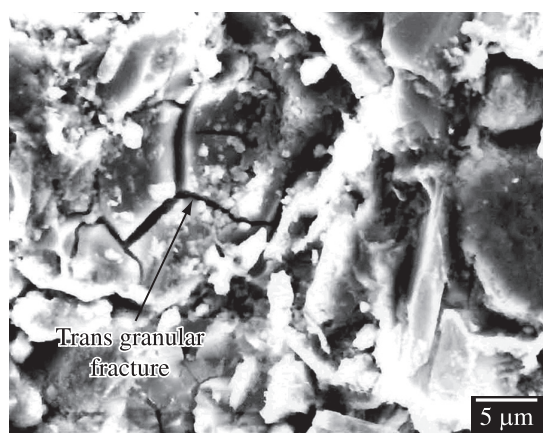

(b)

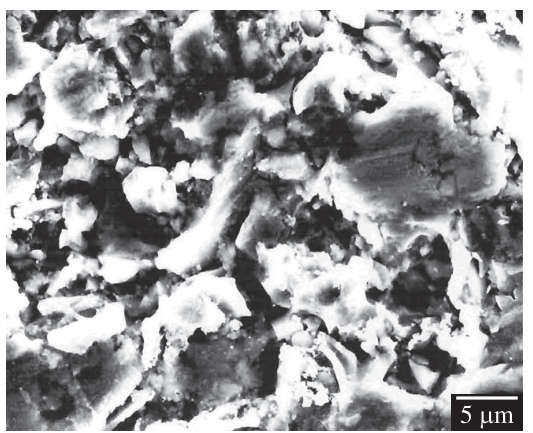

(c)

Figure 6. Scanning electron micrographs of the Al-32Si-2Cu alloy charged at $50 \mathrm{~mA} \cdot \mathrm{cm}^{-2}$ for a) 24 hours; b) 48 hours; and c) 120 hours.

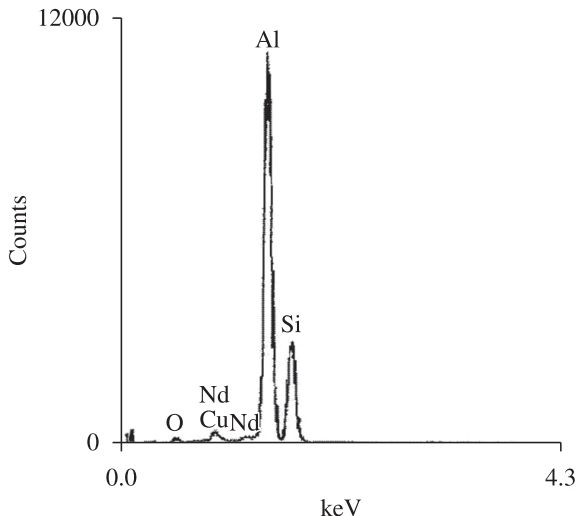

(a)

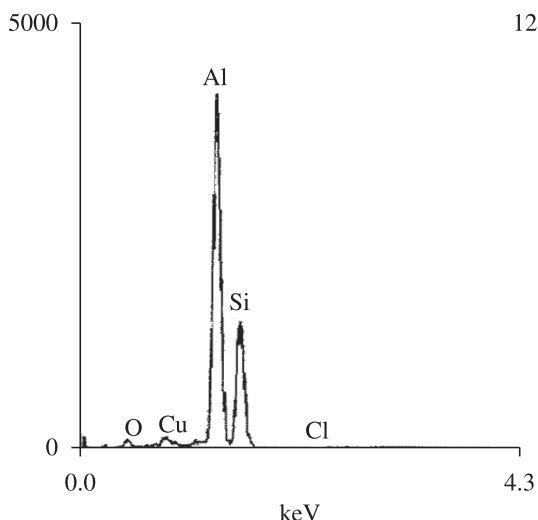

(b)

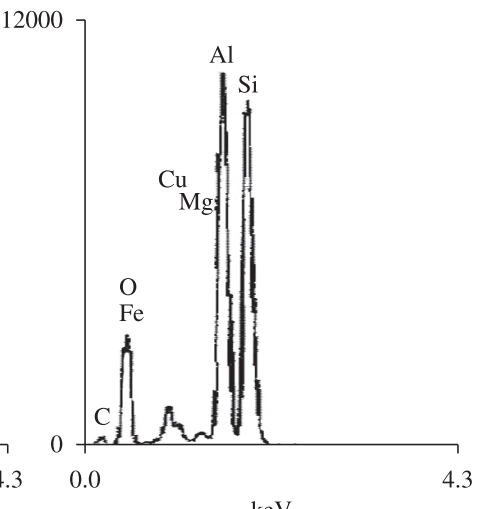

(c)

Figure 7. Compositional changes of the cathodically charged $\mathrm{Al}-32 \mathrm{Si}-2 \mathrm{Cu}$ alloy in $0.1 \mathrm{M} \mathrm{HCl}$ solution a) untreated; b) $25 \mathrm{~mA} . \mathrm{cm}^{-2}$ for 48 hours; and c) $50 \mathrm{~mA} \cdot \mathrm{cm}^{-2}$ for 48 hours.

Table 2. Compositional bending in wt. (\%) of the specimen charged at 25 and $50 \mathrm{~mA} / \mathrm{cm}^{2}$ by EDS analysis

\begin{tabular}{ccccccl}
\hline \multirow{2}{*}{$\begin{array}{c}\text { I } \\
\left(\mathrm{mA} . \mathrm{cm}^{-2}\right)\end{array}$} & \multirow{2}{*}{$\begin{array}{c}\text { Time } \\
\text { (hours) }\end{array}$} & \multicolumn{5}{c}{ Elements in wt. (\%) } \\
\cline { 3 - 7 } Untreated & 0 & 63.5 & 32.8 & 2.4 & 0 & 0 \\
\hline 25 & 24 & 49.0 & 41.8 & 2.8 & 6.8 & 0 \\
& 48 & 53.0 & 27.4 & 3.8 & 15.7 & 0.4 \\
& 120 & 50.5 & 44.0 & 1.8 & 4.7 & 0 \\
\hline 50 & 24 & 69.5 & 23.2 & 2.9 & 6.1 & 0 \\
& 48 & 60.0 & 31.9 & 2.8 & 6.9 & 0 \\
& 120 & 45.0 & 26.7 & 7.1 & 23.7 & 0.3 \\
\hline
\end{tabular}

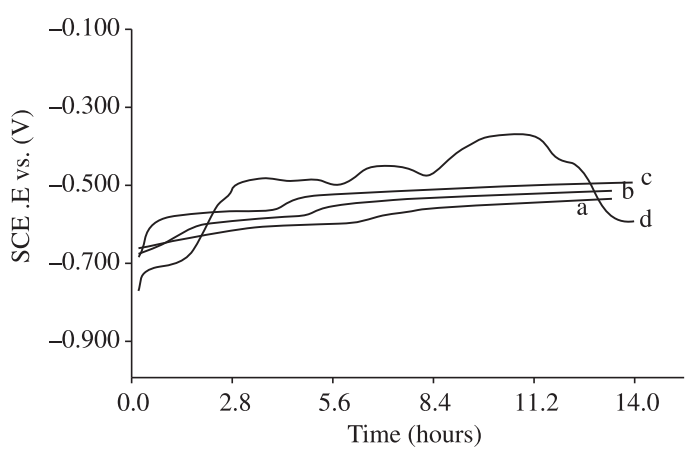

Figure 8. Variation of open circuit potential with time for $\mathrm{Al}-\mathrm{Si}-\mathrm{Cu}$ alloy in a) 0.1 ; b) 1.0 ; c) 2.0 ; and d) $3.0 \mathrm{M} \mathrm{HCl}$ solution. 
stable pits. Isaacs ${ }^{63}$ pointed out that the decrease of OCP during the fluctuations is responsible for anodic growth of pits and the increase of OCP following the decrease arises from the oxygen reduction after pits repassivate. In other cases the minimum fluctuations of OCP indicates the minimum availability of surface defect sites for pit initiation. A partial step for the initiation of pits is the penetration of $\mathrm{Cl}^{-}$ions in the oxide film preferentially at the defect sites on $\mathrm{Al}$ alloy ${ }^{66-69}$, which favors the deformation of protective film such as $\mathrm{Al}_{5} \mathrm{Cl}_{3}(\mathrm{OH})_{12} \cdot 2 \mathrm{H}_{2} \mathrm{O}, \mathrm{Al}(\mathrm{OH})_{2} \mathrm{Cl}, \mathrm{Al}(\mathrm{OH}) \mathrm{Cl}_{2}$ and $\mathrm{AlCl}_{3}^{[5,6]}$. Even though $\mathrm{Al}_{5} \mathrm{Cl}_{3}(\mathrm{OH})_{12} \cdot 2 \mathrm{H}_{2} \mathrm{O}, \mathrm{Al}(\mathrm{OH})_{2} \mathrm{Cl}$ and $\mathrm{Al}(\mathrm{OH}) \mathrm{Cl}_{2}$ are considered to be barrier films and the soluble nature of $\mathrm{AlCl}_{3}$ eventually react chemically with $\mathrm{Cl}^{-}$ions to form $\mathrm{AlCl}_{4}^{-}$ions. The appearance of $\mathrm{AlCl}_{3}$ and $\mathrm{Al}(\mathrm{OH})_{3}$ on the surface of the corroded specimen suggest the occurrence of the following favorable reaction during polarization in solution.

$$
\begin{aligned}
& 2 \mathrm{H}_{2} \mathrm{O}+2 \mathrm{e} \rightarrow \mathrm{H}_{2}+2 \mathrm{OH}^{-} \\
& \mathrm{Al}+3 \mathrm{OH}^{-} \rightarrow \mathrm{Al}(\mathrm{OH})_{3}+3 \mathrm{e} \\
& \mathrm{Al}+3 \mathrm{Cl}^{-} \rightarrow \mathrm{AlCl}_{3}+3 \mathrm{e}
\end{aligned}
$$

Considering the cathodic reactions, it is understood that decreased cathodic current density results from the decrease in the number of defect sites on the surface with an increase in chloride concentration.

\subsubsection{Corrosion potential}

Increasing chloride concentration shifted the corrosion potential toward a more active direction and resulted in an increase in the passive current density. Enhancement of the anodic behavior of the material as well as large shift of active potential is ascertained. These results suggest that the corrosion resistance of the material is reduced as chloride concentration increases. The variation of corrosion characteristics have been attributed both to the influence of and to the increased amount of the electrochemically active $\mathrm{Al}-\mathrm{Cu}$ phase. Hence the pitting potential of the alloy being very sensitive which indicates the chemical stability of the passive film for the Al-Si-Cu alloy was affected by raising chloride concentration. The corrosion potential of the alloy was near $-497 \mathrm{mV}$ in $0.1 \mathrm{M} \mathrm{HCl}$ solution, but in $3.0 \mathrm{M}$ solution it was near $-503 \mathrm{mV}$. For other solutions it was between and the corrosion potential decreased by $-25-50 \mathrm{mV}$, nobler than that of 3.0 M solutions, but their corrosion current was also higher than that of the $2.0 \mathrm{M}$ solution. Other possible reactions in acid media governed by different authors are presented below (Equations 8, 9 and 10).

$$
\begin{aligned}
& \mathrm{e}^{-}+\mathrm{H}^{+}+\mathrm{OH} \rightarrow \mathrm{H}_{2} \mathrm{O} \\
& \mathrm{e}^{-}+\mathrm{H}^{+}+\mathrm{O}_{\mathrm{ad}} \rightarrow \mathrm{OH}_{\mathrm{ad}} \\
& \mathrm{O}_{2}+\mathrm{H}^{+}+\mathrm{O}_{\mathrm{ad}} \rightarrow 2 \mathrm{O}_{\mathrm{ad}}
\end{aligned}
$$

The evolution of chlorine at the anodic reaction has been discussed in many papers (Equations 11, 12, 13 and 14).

$$
\begin{aligned}
& 2 \mathrm{e}^{-}+\mathrm{Cl}_{2} \rightleftarrows 2 \mathrm{Cl}^{-} \\
& \mathrm{e}^{-}+\mathrm{Cl}_{(\mathrm{a})} \rightleftarrows \mathrm{Cl}^{-} \\
& \mathrm{e}^{-}+\mathrm{Cl}^{+}{ }_{(\mathrm{a})} \rightleftarrows \mathrm{Cl}_{(\mathrm{a})} \\
& \mathrm{Cl}_{2(\mathrm{~g})} \rightleftarrows \mathrm{Cl}^{+}+\mathrm{Cl}^{-}
\end{aligned}
$$

The polarization curves obtained for $\mathrm{Al}-32 \mathrm{Si}-2 \mathrm{Cu}$ alloy in $\mathrm{HCl}$ solutions of various concentrations are shown in Figure 9. Change in chloride concentration changes the shapes and position of the polarization curves. Corrosion kinetic parameters such as corrosion current (Ic), corrosion potential (Ec), and Tafel constants (bc and ba) have been evaluated and are presented in Table 3. Shift in OCP and Ecorr towards the negative direction is observed as the concentration of $\mathrm{HCl}$ is increased. Values of corrosion current/corrosion rate reveal that the alloy corrodes poorly in $3.0 \mathrm{M} \mathrm{HCl}$ and is severely affected in $0.1 \mathrm{M} \mathrm{HCl}$ which is also confirmed from the lowest and highest values of Icorr and corrosion rate. For other cases these values are lying inbetween. A systematic variation of Tafel slopes was not observed as concentration of $\mathrm{HCl}$ increased. Higher hydrogen evolution reaction rate at the cathode increases the exchange current density of the $\mathrm{H}+/ \mathrm{H}$, possibly shifting the cathodic curve in a greater extent which is evident from highest values of bc. Further, Table 3 also shows the shift in Ec values to more anodic direction with increase in concentration of $\mathrm{HCl}$ solution. The highest and lowest corrosion potential values for $0.1 \mathrm{M}$ and $2.0 \mathrm{M} \mathrm{HCl}$ solutions reveal the tendency of passivation. A substantial increase in critical corrosion current values is observed up to $2.0 \mathrm{M}$. This is due to the uniform dissolution of microcrystalline phases present in the matrix of the alloy, which allows the preferential

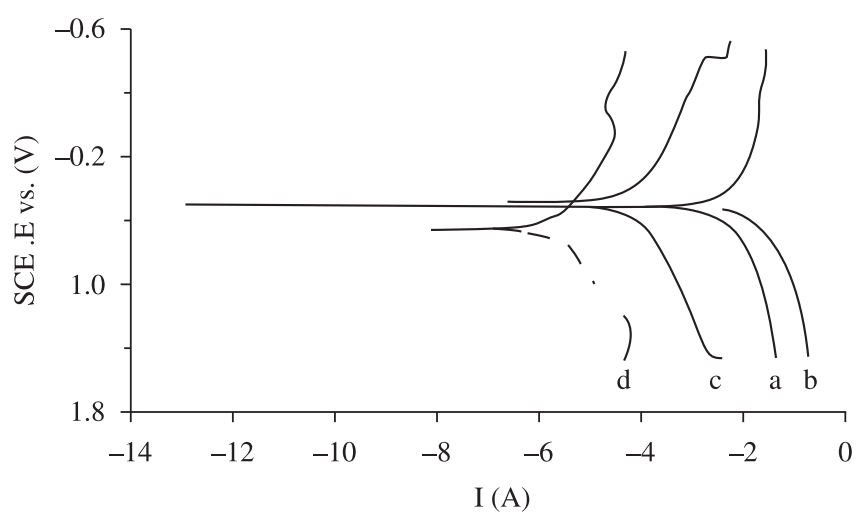

Figure 9. Potentiodynamic polarization plot for $\mathrm{Al}-\mathrm{Si}-\mathrm{Cu}$ alloy in a) 0.1 ; b) 1.0 ; c) 2.0 and d) $3.0 \mathrm{M} \mathrm{HCl}$ solution at a scan rate of $1 \mathrm{mV} / \mathrm{sec}$.

Table 3. Corrosion parameters obtained from potentiodynamic polarization curves for Al-32Si-2Cu alloy in hydrochloric acid solution.

\begin{tabular}{ccccccc}
\hline $\begin{array}{c}\text { Concentration } \\
(\mathrm{M})\end{array}$ & $\begin{array}{c}\text { Eocp* } \\
(-\mathrm{mV})\end{array}$ & $\begin{array}{c}\mathrm{Ec} \\
(\mathrm{mV})\end{array}$ & $\begin{array}{c}\mathrm{Ic} \\
\mathrm{mA} \cdot \mathrm{cm}^{-2}\end{array}$ & $\begin{array}{c}\mathrm{b}_{\mathrm{c}} \\
\mathrm{mV} \cdot \mathrm{dec}^{-1}\end{array}$ & $\begin{array}{c}\mathrm{b}_{\mathrm{a}} \\
\mathrm{mV}^{*} \mathrm{dec}^{-1}\end{array}$ & $\begin{array}{c}\text { Corrosion rate } \\
\left(\mathrm{mpy}^{2}\right.\end{array}$ \\
\hline 0.1 & 497 & 494 & 1824 & 213 & 298 & 4060 \\
1.0 & 477 & 469 & 5140 & 234 & 176 & 11440 \\
2.0 & 452 & 466 & 33.9 & 210 & 271 & 75.5 \\
3.0 & 503 & 588 & 1.9 & 215 & 285 & 4.4
\end{tabular}

Eocp: open circuit potential; Ec: corrosion; potential; Ic: corrosion current; ba and bc: Tafel slopes of anodic and cathodic curves.

*All potentials were measured against a saturated calomel electreode 


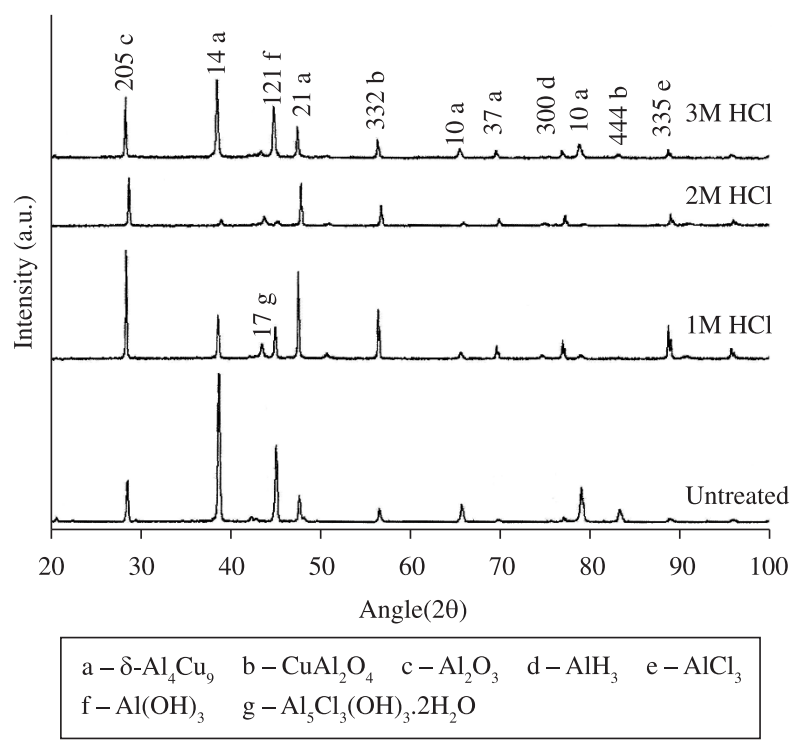

Figure 10. X-ray diffraction patterns of the surface film formed on $\mathrm{Al}-32 \mathrm{Si}-2 \mathrm{Cu}$ alloy after polarization in $\mathrm{HCl}$ solutions.

dissolution of crystalline phases. A sharp increase in current at metal dissolution current density in Figure 9 is not consistent in $3.0 \mathrm{M} \mathrm{HCl}$ solution due to the change of passivating ability of phases. Further, the rapid increase in oxidation current indicates surface build-up at the metal/oxide film interface because of the rate difference of introduction into and transport through the oxide film of $\mathrm{Al}^{3+}$ ions in the case of $\mathrm{Al}$ dissolution into the alkaline solution. As the electrode potential is made to be more positive, the charge transfer reaction at the metal/oxide film interface proceeds more rapidly compared to oxide film dissolution. Therefore, the thickness of oxide film on the $\mathrm{Al}$ surface increases at the more positive electrode potential and thus, resistance of surface oxide film increases.

The formation of simple and mixed salts such as $\mathrm{AlCl}_{3}$, $\mathrm{Al}_{5} \mathrm{Cl}_{3}(\mathrm{OH})_{12} .2 \mathrm{H}_{2} \mathrm{O}$, over the alloy surface by chloride inclusion in the major corrosion product of hydroxides or oxides of $\mathrm{Al}$ have also been ascertained from the XRD patterns of the corrosion product (Figure 10). The occurrence of aluminum chlorides are less stable compared to the aluminum hydroxides or oxides and therefore react further thereby liberating chloride so that the corrosion process becomes a continuous one.

\section{Conclusions}

Based on cathodic charging and potentiodynamic polarization experiments the following important conclusions have been proposed:

- The susceptibility of embrittlement behavior for Al-Si-Cu alloy through the crack propagation process is more pronounced in high charging time of 120 hours and high current density.

- Over loaded hydrogen in the alloy particularly at high charging time and current density develops a partial reversible transformation of microcrystalline to nanocrystalline transformation.

- The decrease in cathodic current density with increasing $\mathrm{Cl}^{-}$ion concentrations presumably due to the enhanced attack of $\mathrm{Cl}^{-}$ ions for film repairing processes with relatively low electronic conductivity formed at the surface defects.

- Formation of simple and mixed salts such as $\mathrm{AlCl}_{3}$, $\mathrm{Al}_{5} \mathrm{Cl}_{3}(\mathrm{OH})_{12} \cdot 2 \mathrm{H}_{2} \mathrm{O}$ over the alloy surface was reasoned out with possible electrochemical reactions.

\section{References}

1. Mabie HH, Wilson JH, Louthan MR and Kauffman CJ. The effect of absorbed hydrogen on torsional fatigue of 2024-T351 aluminum alloy. Scripta Metallurgica. 1983; 17(1):59-62.

2. Magnin $T$ and Rieux P. The relation between corrosion fatigue and stress corrosion cracking in aluminum-zinc-magnesium alloys. Scripta Metallurgica. 1987; 21(7):907-911.

3. Magnin T and Coudreuse L. Corrosion fatigue mechanisms in bcc stainless steels. Acta Metallurgica. 1987; 35(8):2105-2113.

4. Hardie D, Holroyd NJH and Parkins RN. Reduced ductility of highstrength aluminum alloy during or after exposure to water. Metal Science. 1979; 13(11):603-610.

5. Zohdi TI and Meletis EI. On the intergranular hydrogen embrittlement mechanism of aluminum-lithium alloys. Scripta Metallurgica Materialia. 1992; 26(10):1615-1620.

6. Solovioff G, Eliezer D and Lavernia EJ. Hydrogen effects in (aluminumtitanium)-silicon carbide particle metal matrix composites. Materials Science Engineering A. 1992; A159(2):237-242.

7. Christodoulou L and Flower HM. Hydrogen embrittlement and trapping in aluminum-6\% zinc-3\% magnesium. Acta Metallurgica. 1980; 28(4):481487.

8. Holroyd NJH and Hardie D. Strain-rate effects in the environmentally assisted fracture of a commercial high-strength aluminum alloy. Corrosion Science. 1981; 21(2):129-144.

9. Ricker RE and Duquette DJ. The role of hydrogen in corrosion fatigue of high-purity aluminum-zinc-magnesium exposed to water vapor. Metallurgical Transactions A. 1988; 19A(7):1775-1783.

10. Chene J, Bernstein IM and Thompson AW. Role of heat treatment and cathodic charging conditions on the hydrogen embrittlement of HP 7075 aluminum alloy. Metallurgical Transactions A. 1990; 21A(2):455-464.

11. Nguyen D, Thompson AW and Bernstein IM. Microstructural effects on hydrogen embrittlement in a high-purity 7075 aluminum alloy. Acta Metallurgica. 1987; 35(10):2417-2425.

12. Smith III EF and Duquette DJ. The effect of cathodic polarization on the corrosion fatigue behavior of a precipitation-hardened aluminum alloy. Metallurgical Transactions A. 1986; 17A(2):339-347.

13. Ford FP. Quantitative examination of slip-dissolution and hydrogenembrittlement theories of cracking in aluminum alloys. Metal Science. 1978;12(7):326-334.

14. Ford FP. Corrosion fatigue crack propagation in aluminum- $7 \%$ magnesium alloy. Corrosion. 1979; 35(7):281-287.

15. Panagopoulos, $\mathrm{CN}$ and Georgiou EP. The effect of hydrogen charging on the mechanical behaviour of 5083 wrought aluminum alloy. Corrosion Science. 2007; 49(12): 4443-4451.

16. Watson JW, Shen YZ and Meshii M. Effect of cathodic charging on the mechanical properties of aluminum. Metallurcial Transactions A. 1988; 19A(9):2299-2304.

17. Tuck CDS. The embrittlement of aluminum-zinc-magnesium and aluminum-magnesium alloys by water vapor. Metallurgical Transactions A. $1985 ; 16$ A(8): 1503-1514.

18. Albrecht J, Thompson AW and Bernstein IM. The role of microstructure in hydrogen-assisted fracture of 7075 aluminum. Metallurgical Transactions A. $1979 ; 10$ A(11):1759-1766.

19. Albrecht J, Thompson AW and Bernstein IM. Evidence for dislocation transport of hydrogen in aluminum. Metallurgical Transactions A. 1982; 13(5):811-820.

20. Ohnishi T and Shinkai Y. Effect of cathodic hydrogen charging on mechanical properties of pure aluminum. Keikinzoku. 1993; 43(4):230233.

21. Mueller MP, Thompson AW and Bernstein IM. Stress corrosion behavior of 7075 aluminum in $1 \mathrm{~N}$ aluminum chloride solutions. Corrosion. 1985; 41(3):127-136.

22. Heikkenen HC, Shiong LF and Starke EA. The low cycle fatigue behavior of high strength 7XXX-type aluminum alloys in the T7351 condition. Materials Science Enginnering. 1981; 51(1):17-23. 
23. Holroyd NJH and Hardie D. Factors controlling crack velocity in 7000 series aluminum alloys during fatigue in an aggressive environment. Corrosion Science. 1983; 23(6):527-546.

24. Piascik RS and Gangloff RP. Environmental fatigue of an aluminumlithium-copper alloy: Part II. Microscopic hydrogen cracking processes. Metallurgical Transactions A. 1992; 24A(12):2751-2762.

25. Hoar TP, Mears DC and Rothwell GP. The relationships between anodic passivity, brightening, and pitting. Corrosion Science. 1965; 5(4):279-289.

26. Boehni $\mathrm{H}$ and Uhlig $\mathrm{HH}$. Environmental factors affecting the critical pitting potential of aluminum. Journal of the Electrochemical Society. 1969; 116(7):906-910.

27. Nguyen TH and Foley RT. The chemical nature of aluminum corrosion. III. The dissolution mechanism of aluminum oxide and aluminum powder in various electrolytes. Journal Electrochemical Society. 1980; 127(12):2563-2566.

28. Foley RT. The chemical nature of aluminum corrosion. V. Energy transfer in aluminum dissolution. Journal Electrochemical Society. 1982; 129(3):464-467.

29. Kim JD and Pyun SI. Effects of electrolyte composition and applied potential on the repassivation kinetics of pure aluminum. Electrochimica Acta. 1995; 40(12):1863-1869.

30. McCafferty E. The electrode kinetics of pit initiation on aluminum Corrosions Science. 1995; 37(3):481-492.

31. Pyun SI and Lee EJ. Effect of halide ion and applied potential on repassivation behavior of Al-1 wt.\% Si-0.5wt.\%Cu alloy. Electrochimica Acta. 1995; 40(12):1963-1970.

32. Despic AR, Drazic DM, Purenovic MM and Cikovic N. Electrochemical properties of aluminum alloys containing indium, gallium and thallium. Journal of Applied Electrochemistry. 1976; 6(6):527-542.

33. Horn Y, Takao J and Shomon H. Aluminum alloys for aluminum primary cell. Electrochimica Acta. 1985; 30(9):1121-1124.

34. Blurton KF and Sammets AF. Metal/air batteries: their status and potential - a review. Journal of Power Sources. 1979; 4(4):263-279.

35. Abouimrane A, Ding J and Davidson IJ. Liquid electrolyte based on lithium bis-fluorosulfonyl imide salt: Aluminum corrosion studies and lithium ion battery investigations. Journal of Power Sources. 2009; 189(1):693-696.

36. Kohno K, Koishikawa Y, Yagi Y and Horiba T. Development of an Aluminum-laminated Lithium-ion battery for Hybrid electric vehicle application. Journal of Power Sources. 2008; 185(1):554-558.

37. Hebert K and Alkire R. Growth and passivation of aluminum etch tunnels. Journal of Electrochemimical Society. 1988; 135(9):2146-2157.

38. Lin CF and Hebert KR. The effect of prior cathodic polarization on the initiation of pitting on aluminum. Journal of Electrochemimical Society. 1990; 137(12):3723-3230.

39. Hepel T, Pollak FH and Grady WEO. Chlorine evolution and reduction processes at oriented single-crystal ruthenium dioxide electrodes. Journal of Electrochemimical Society. 1986; 133(1):69-75.

40. Khadon AA, Yaro AS, Kadum AAH, AlTaie AS and Musa AY. The effect of temperature and acid concentration on corrosion of low carbon steel in hydrochloric acid media. American Journal of Applied Sciences. 2009; 6(7):403-1409.

41. Hurren T, Lian H, Odegard OS and Valand T. Corrosion and passive behavior of aluminum in weakly acid solution. Electrochimica Acta. 1984; 29:579-585.

42. Scamans G. Development of the aluminum /air battery. Chemistry \& Industry. 1986; 6:192-196.

43. Macdonald DD, Real S, Smedley SI and Urquidi-Macdonald M Evaluation of alloy anodes for aluminum -air batteries. IV. Electrochemical impedance analysis of pure aluminum in $4 \mathrm{M}$ potassium hydroxide at 25 ${ }^{\circ}$ C. Journal of Electrochemical Society. 1988; 135(10):2410-2414.

44. Drazic DM, Zecevic SK, Altanasoki RT and Despic AR. The effect of anions on the electrochemical behavior of aluminum. Electrochimica Acta. 1983; 28(5):751-755.

45. Marichev VA and Lunin VV. Anomalous isotope effect during hydrogen embrittlement of titanium and aluminum alloys in electrolytes. Elektroknimiya. 1990; 26(3):343-345.
46. Gray HR. Testing for hydrogen environment embrittlement. Experimental variables. American Society for Testing and Materials, Special Technical Pulications. 1974; STP 543:133-151.

47. Takano N. Hydrogen diffusion and embrittlement in 7075 aluminum alloy. Materials Science and Engineering A. 2008; A483-A484:336-339.

48. Shuhei O, Nobuhiro M, Katsuyuki K, Koji I, Goroh I and Hitoshi Y. Embrittlement properties of aluminum alloys 7075 and 6061 in highpressure gaseous hydrogen. Nippon Kikai Gakkai Ronbunshu. 2009; 75(751):366-372

49. Bannoush A and Vehoff $\mathrm{H}$. Hydrogen embrittlement of aluminum in aqueous environments examined by in situ electrochemical nanoindentation. Scripta Materiallia. 2008; 58(9):747-750.

50. Kmoutsi H, Haidemenopoulos GN, Bontozoglou V and Pantelakis S. Corrosion-induced hydrogen embrittlement in aluminum alloy 2024 Corrosion Science. 2006; 48(5):1209-1224.

51. Lu G and Kaxiras E. Hydrogen Embrittlement of Aluminum: The Crucial Role of Vacancies. Physical Review Letters. 2005; 94(15):155501/1$155501 / 4$.

52. Lunarska E. and Chernyaeva O. Effect of precipitates on hydrogen transport and hydrogen embrittlement of aluminum alloys. Materials Science. 2004; 40(3):399-407.

53. Petroyiannis PV, Kermanidis AT, Papanikos P and Pantelakis SG. Corrosion-induced hydrogen embrittlement of 2024 and 6013 aluminum alloys. Theoretical and Applied Fracture Mechanics. 2004; 41(1-3):173183.

54. Hu J, Chu WY, Ren WC, Yao CK and Qiao LJ. Stress corrosion cracking and hydrogen embrittlement of whisker-reinforced aluminum composites. Corrosion. 2004; 60(2):181-186.

55. Yuan J and Xiongpu WH. Hydrogen embrittlement susceptibility of 8090 aluminum lithium alloy. Cailiao Baohu. 1999; 32(12):29-30.

56. Bond GM, Robertson IM and Birnbaum HK. Effects of hydrogen on deformation and fracture processes in high-purity aluminum. Acta Metallurgica. 1988; 36(8):2193-2197.

57. Thakur C and Balasubramaniam R. Hydride formation in an Al-Li alloy on cathodic hydrogen charging. Scripta Materiallia. 1997; 36(3): 311-316.

58. Piperpoint CA, Sudarshan TS, Louthan MR and Place TA. Hydrogen susceptibility of a manganese- aluminum austenitic stainless steel. Microstructural Science. 1987; 14:423-435.

59. Hardwick DA, Taheri M, Thompson AW and Bernstein IM. Hydrogen embrittlement in a 2000-series aluminum alloy. Metallurgical Transactions A. 1982; 13A(2):235-239.

60. Hardwick DA, Bernstein IM and Thompson AW. The effect of copper content and microstructure on the hydrogen embrittlement of Al- $6 \mathrm{Zn}-2 \mathrm{Mg}$ alloys. Metallurgical Transactions A. 1983; 14A(12):2517-2526.

61. Lin CF, Porter MD, Marc D and Hebert KR. Surface films produced by cathodic polarization of aluminum. Journal Electrochemical Society. 1994; 141(1):96-104.

62. Lin CF and Hebert KR. Changes produced by cathodic polarization in the electrical conduction behavior of surface films on aluminum. Journal Electrochemical Society. 1994; 141(1):104-110.

63. Isaacs HS. The localized breakdown and repair of passive surfaces during pitting. Corrosion Science. 1989; 29(2-3):313-323.

64. Su P and Devereux OF. Impedance characterization of crevice corrosion of an aluminum 2024 structure. Corrosion. 2003; 59(9):780-789.

65. Moon SM and Pyun S. Faradaic reactions and their effects on dissolution of the natural oxide film on pure aluminum during cathodic polarization in aqueous solutions. Corrosion. 1998; 54(7):546-552.

66. Zaid B, Said D, Benzaid A and Hadji S. Effects of $\mathrm{pH}$ and chloride concentration on pitting corrosion of AA6061 aluminum alloy. Corrosion Science. 2008; 50(7):1841-1847.

67. Prater WL. Pitting corrosion of cast metallurgy aluminum-beryllium alloys in sulfuric acid solutions. Corrosion. 2008; 64(6):517-531.

68. Tosun A, Ergun M, Balbai M and Tamirci M. The use of experimental design method for the investigation of pitting potential of aluminum. Materials Corrosion. 2007; 58(7):502-505.

69. McCafferty E. Sequence of steps in the pitting of aluminum by chloride ions. Corrosion Science. 2003; 45(7):1421-1438. 
